\title{
EPILEPSIA DO LOBO TEMPORAL E AURA COM ALEGRIA E PRAZER RELATO DE DOIS CASOS E REVISÃO DE LITERATURA
}

\author{
EDSON J. AMÂNCIO*,SAMUEL I ZYMBERG*, MARA F. CHIAR! PIRES*
}

RESUMO: São apresentados 2 casos de epilepsia do lobo temporal nos quais os pacientes apresentam sensações de alegria e prazer durante a crise. Os autores analisam a evolução do conceito de aura epilética e discutem a controvertida questão da epilepsia em Dostoiévski, fazendo revisão da literatura sobre a existência do prazer e do êxtase como manifestação da doença.

PALAVRAS-CHAVE: epilepsia, lobo temporal, aura com alegria e prazer, Dostoiévski.

Temporal lobe epilepsy and aura with happiness and pleasure: report of two cases and literature revision

SUMMARY - The authors present two cases of temporal lobe epilepsy with happiness and pleasure during the seizure. Discussing the rarity of these clinical findings, the concept of epileptic aura is historically reviewed with special attention to Dostoiévski's epilepsy and its descriptions by the medical literature.

KEY WORDS: epilepsy, temporal lobe, aura with happiness and pleasure.

Os epileptologistas em geral admitem que manifestações psíquicas fugazes de alegria ou prazer raramente ocorrem em epiléticos, sendo mais comuns as sensações desagradáveis de ansiedade, pavor e medo nas crises associadas à epilepsia do lobo temporal $*^{1} *^{6} *^{10} *^{12,14} n^{24}$. Por outro lado, há discordância na literatura quanto à existência do êxtase ou euforia como sintoma da doença. ${ }^{2} *^{8} *^{17} *^{20124217,32} *^{33}$. Num extraordinário artigo sobre o assunto Gastaut ${ }^{22}$ faz uma análise histórica da evolução do conceito de aura e, numa demonstração inequívoca de seriedade científica, confessa ter sido um dos principais responsáveis pela divulgação do mito da aura extática, inspirado na epilepsia do escritor russo Fiodor Dostoiévski.

O objetivo do presente estudo é discutir a existência dos sintomas alegria e prazer como possíveis manifestações criticas da epilepsia do lobo temporal a partir de dois casos relatados, bem como analisar as opiniões conflitantes encontradas na literatura científica sobre o tema.

\section{RELATO DOS CASOS}

Caso 1. AFSJ, 31 anos, casado, brasileiro, profissão artista plástico, natural de São Vicente SP. Portador de epilepsia desde 1983 quando teve a primeira crise convulsiva generalizada durante o sono. As crises são de frequência variável (2-3/mês) e na maioria das vezes se iniciam por sensações de desconforto abdominal e outras "difíceis de descrever"; "é como se fosse um prazer, um orgasmo", que dura sempre poucos segundos. Às vezes tem alucinações repentinas e de curta duração. Outras vezes sente um cheiro estranho, desagradável. Nos dias em que apresenta essas sensações fica emotivo, chora sem razão aparente. Inclui entre os sintomas sensações de volta ao passado, o "déjàvecu". O avô materno tinha "ataques". Toma irregularmente $250 \mathrm{mg}$ de fenitoina/dia. Refere ainda ausências fugazes. O EEG realizado em vigília mostraespículas isoladas no lobo temporal esquerdo (Fig 1). Recusou-se a submeter-se

•Pós-graduando em Neurocirurgia, Escola Paulista de Medicina (EPM); **Psicóloga do Departamento de Psicologia da Universidade Católica de Santos (UNISANTOS). Aceite: 13-novembro-1993.

Dr. Edson José Amâncio - Avenida Epitácio Pessoa 117-11045-301 Santos SP - Brasil. 


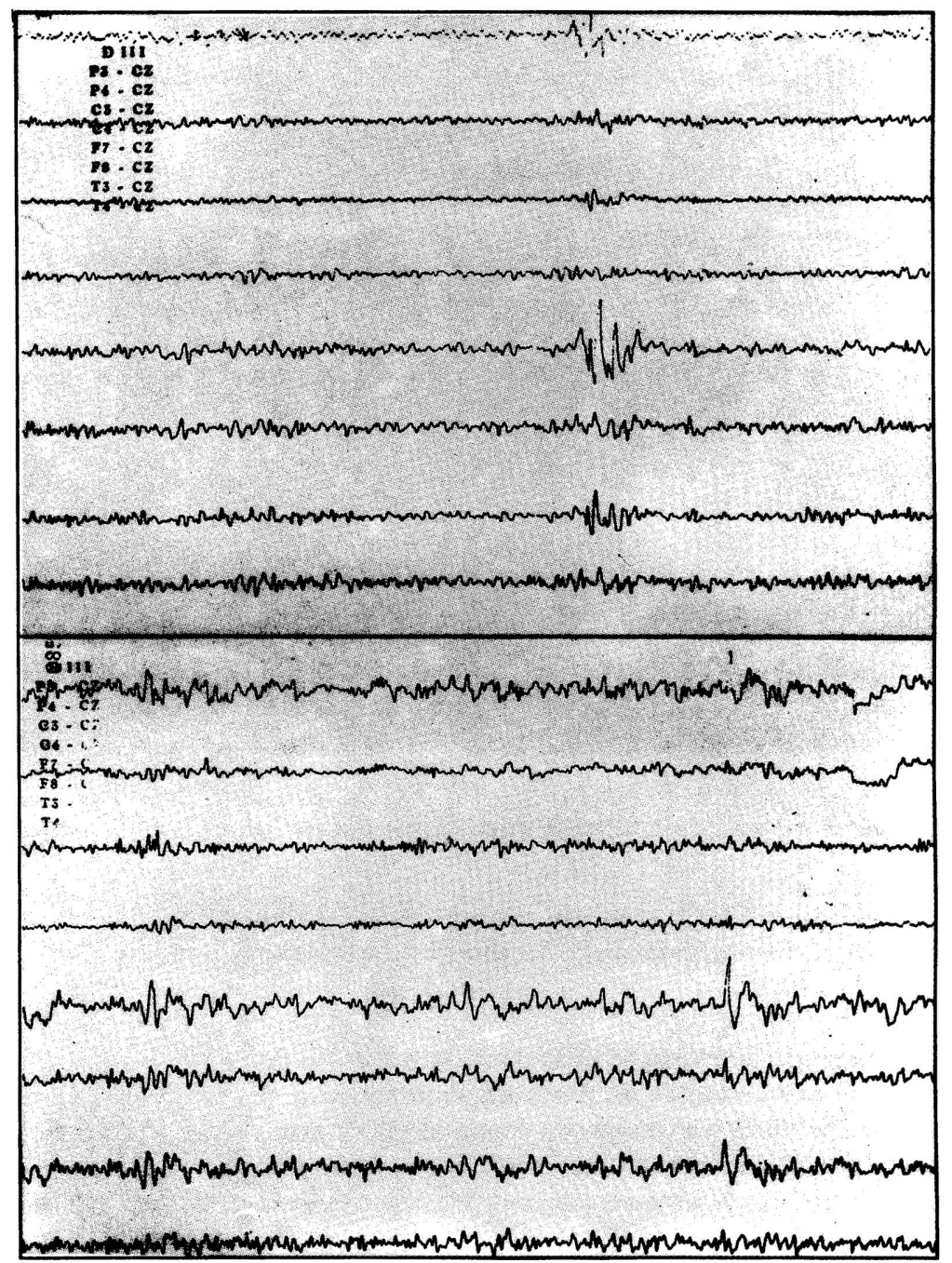

Fig 1. Caso 1 ( no alto): EEG com espículas nas áreas temporais à esquerda. Caso 2 (em baixo): EEG com "ponta-onda" nas áreas temporais à esquerda.

a TC ou RNM. O exame neurológico é normal. O exame psiquiátrico mostra paciente comunicativo, inteligente, orientado têmporo-espacialmente, vestido adequadamente, concatenando as idéias, expressando os pensamentos com clareza. Indagado porque tomava irregularmente a medicação respondeu: "por receio de ficar com a criatividade diminuída".

Caso 2. ACC, 29 anos, masculino, branco, casado, escriturário, natural de Cubatão SR Crises convulsivas desde os 15 anos de idade. As crises são do tipo ausências de curta duração e automatismos simples, gestuais, mastigatórios ou deambulação. Frequência de $1 /$ mês. Às vezes as crises se iniciam por desconforto abdominal acompanhado de náuseas e evacuação ou micção imperiosa. Outras vezes se resumem a sensações estranhas porém agradáveis: "é gostoso", "é bom", "duram pouco tempo". "Não é como o prazer sexual", "é como se eu pudesse ficar um pouco junto do meu pai que já morreu, só que, logo depois, me dá sono, uma leve dor de cabeça e uma vontade de urinar". Ocasionalmente apresenta convulsões noturnas. Refere ainda que, em situações especiais de tensão emocional, pode provocar estas crises. Sobretudo se estiver "numa situação difícil" ou "qualquer momento negativo". Vários EEGs realizados mostraram foco de espícula no lobo temporal esquerdo (Fig 1). TC mostra áreas de 


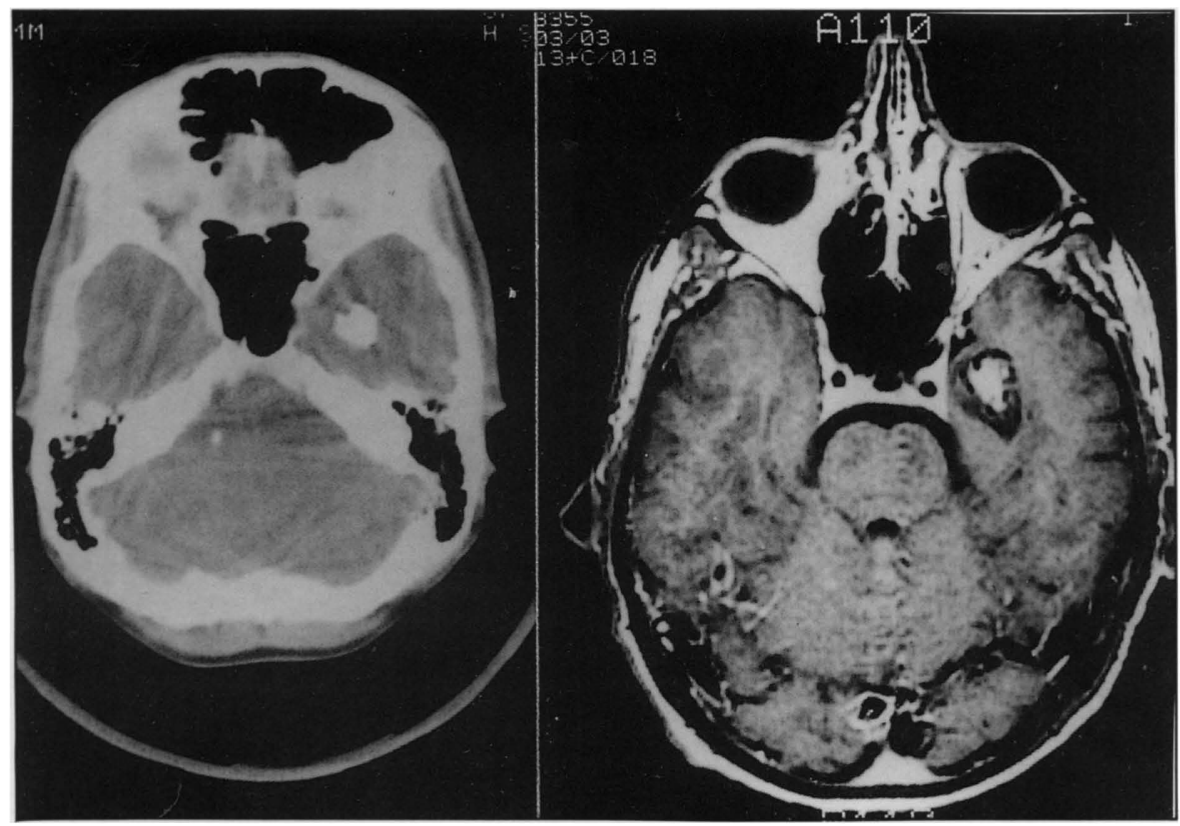

Fig 2. Caso 2. À esquerda, TC mostrando área arredondada, calcificada, na região ínfero-mesial do lobo temporal esquerdo. À direita, RNM mostrando área de lesão ínfero-mesial do lobo temporal esquerdo.

calcificações correspondendo à porção anterior do lobo temporal esquerdo (Fig 2). RNM confirma os achados da TC (Fig 2): a lesão é sugestiva de oligodendroglioma ou hamartoma. Paciente recusou biópsia ou cirurgia.

\section{COMENTÁRIOS}

A questão principal é saber se os sintomas referidos são devidos a descarga epiléptica no lobo temporal ou manifestações psíquicas de outra natureza. Essa distinção, absolutamente necessária ao diagnóstico e à orientação da terapia adequada, nem sempre pode ser realizada com segurança. No Caso 1 o paciente tem uma "explicação" pessoal para suas crises, havendo inclusive receio manifesto de vê-las desaparecer por completo com o tratamento medicamentoso, fazendo-o portanto "perder a criatividade" ou "inspiração" no seu trabalho de artista plástico.

É interessante assinalar que os dois pacientes relatados às vezes procuram deliberadamente desencadear a própria crise através de algum artifício, geralmente um pensamento forçado, uma idéia persistente. No Caso 2 o paciente faz tais tentativas com o propósito de obter prazer, embora saiba que a sensação de prazer - caso ocorra - será breve e poderá seguir-se de convulsão. Refere ainda que tenta desencadear a crise para escapar a situações embaraçosas ou desagradáveis a que esteja exposto circunstancialmente (como discussões, brigas familiares, repreensão no trabalho). No Caso 1 essas tentativas têm o objetivo explícito de obter prazer e "criar um clima propício para a criatividade". Nos dois casos a maioria dessas tentativas falham, embora uma ou outra vez seus esforços possam ser recompensados, segundo suas próprias afirmações. Ambos são enfáticos ao expressarem o desejo de se livrarem das convulsões. No Caso 2 as crises convulsivas foram controladas com medicação ( $750 \mathrm{mg}$ de primidona/dia, divididos em 3 tomadas $+250 \mathrm{mg}$ de fenitoína ingeridas a noite), no entanto as crises parciais complexas com automatismo psicomotor continuam a ocorrer com frequência, interferindo na atividade diária do paciente, sendo as manifestações de alegria, bem-estar e prazer de ocorrência ocasional. É relevante observar que no Caso 2 as efêmeras manifestações de alegria e prazer podem vir acompanhadas de evocações afetivas efetivamente vivenciadas, como quando relata "é como se eu pudesse ficar um pouco junto do meu pai que já 
morreu (...)"• Tais afirmações nos remetem inevitavelmente à associação com sintomas neuróticos de perdas, frustração etc, tornando o terreno ainda mais movediço, dificultando uma conclusão definitiva. No entanto, embora o polimorfismo dos sintomas e a subjetividade deles, bem como a presença de reações neuróticas sejam frequentes nesses pacientes e sirvam, portanto, de obstáculo à interpretação correta das queixas, o fato de ocorrerem ocasionalmente, serem de curta duração e se fazerem acompanhar na maioria das vezes de outras manifestações epiléticas "maiores" (convulsões, automatismos), nos inclinam a admitir os sintomas discutidos nos Caso 1 e 2 como possíveis manifestações de descargas epiléticas do lobo temporal.

Segundo Gastaut ${ }^{22}$ a primeira referência sobre crise epilética na qual a aura é um dos sintomas iniciais se encontra no livro de Herpin $(1852)^{26}$ o qual contém um capítulo inteiro dedicado ao assunto. Cita Aretaeus como o primeiro a descrever "crise epilética começando com uma dolorosa contração, entorpecimento e movimentos bruscos propagando-se dos dedos ou dos artelhos para a cabeça". Galeno, também citado por Herpin, confirmou as observações de Aretaeus relatando que "um homem jovem e inteligente conservou a consciência durante o ataque e pôde assim descrever o que sentia". No seu relato contou que o início do ataque era uma sensação estranha vindo das extremidades em direção à cabeça e comparou-a à uma névoa fria (Aura quoedam frigida).

No mesmo trabalho Gastaut enfatiza o papel desempenhado pelas crises epiléticas atribuidas ao escritor russo Fiodor Mikhaialovitch Dostoiévski, na origem desse controvertido dado clínico na literatura médica. Segundo Gastaut houve evolução no conceito de aura como epifenômeno de algumas manifestações epiléticas. Suas pesquisas mostraram: (a)ausência de qualquer referência à aura emocional com sensação de alegria e, por extensão, êxtase, até o final do século passado; (b) a descoberta pelos médicos, no começo do século XX, da aura extática em Dostoiévski, considerada como fenômeno isolado e particular, não pode ser generalizada; (c) a introdução injustificada do conceito de aura com alegria ou êxtase, no arsenal dos sintomas epiléticos, relatado na descoberta da epilepsia do lobo temporal na metade do século.

Para Gastaut o conceito de aura como sintoma inicial de algumas formas de epilepsia foi substancialmente ampliado durante a segunda metade do século XIX. Cita o trabalho de Delasiauve ${ }^{10}$ publicado em 1854, que relaciona 183 auras em 264 epiléticos (69\% de incidência) separando-as em várias categorias de acordo com o sintoma inicial envolvendo a cabeça, o tórax, abdome, extremidades, ou genitália. Cita ainda Hammond que, em 1873, encontrou 128 auras em 236 pacientes $(54 \%)$ entre os quais descreveu um número de sintomas psicosensoriais (ilusões, alucinações visuais, etc) mas não um sintoma isolado psicoafetivo.

Gastaut reserva os maiores elogios para os trabalhos de Jackson que durante os anos 18761890, descreveu a aura psíquica. A assim chamada (por Gastaut) aura intelectual foi agrupada por Jackson sob a denominação de "dream state" e inclui: (a) a sensação de falsa relembrança dando ao sujeito a sensação de já ter visto, o "déjà-vu", ou escutado, o "déjà-entendu", ou ainda sensações de já ter experimentado determinada vivência, o "déjà-vecu"; (b) a sensação inversa, dando ao paciente a impressão de desconhecimento, de jamais ter visto, escutado ou vivenciado uma experiência conhecida, o "jamais-vu", "jamais-vecu"; (c) o fenômeno do pensamento forçado, o qual obriga o paciente a concentrar sua atenção num determinado pensamento que ele é incapaz de identificar posteriormente; (d) o fenômeno inverso, consistindo em fugas de idéias. Para Jackson ${ }^{2 *}$ as raras auras emocionais estavam limitadas à sensação de pavor às quais em 1887 deu a seguinte descrição: "Há uma sensação de pavor.(Não quero dizer que isto significa medo do ataque, mas um tipo de medo que vem de si mesmo). É um estado psíquico altamente complexo e, sugiro, não ocorre de maneira súbita, mas nasce através de descargas leves oriundas de agrupamentos nervosos muito complexos representando partes do corpo, especialmente partes orgânicas, concernentes com a manipulação do medo."

Entre os trabalhos selecionados Gastaut cita o de Gowers (1881 $)^{25}$,que dedicou 50 páginas do seu tratado de epilepsia para o estudo de 505 pacientes com aura epilética e encontrou 15 casos 
(3\%) com aura emocional. Escreveu em suas memórias: "A aura emocional, em todos os casos, tem a forma do pânico-alarme vago ou terror intenso", e o livro sobre epilepsia escrito por Voisin $(1897)^{36}$ que tinha uma sessão dedicada às auras psíquicas ("reminiscências de eventos prévios"; "experiências semelhantes a sonhos", "idéias fixas"). Quanto às auras emocionais, Voisin menciona somente aquelas em que os pacientes se queixavam de "depressão, ansiedade, ou desejo de morte".

Pode-se concluir portanto, pela revisão de Gastaut, que até o final do século XIX as auras com sintomas emocionais eram conhecidas, mas somente na forma de desprazer, mudanças na afetividade sugerindo apreensão, pavor ou angústia. Não estava formulado ainda o conceito de prazer, sensação agradável e, por extensão, aura extática, embora Jackson tenha aludido a sensações de prazer durante auras intelectuais. Jackson, entretanto, considerou cada sensação um epifenómeno acompanhando o estado de sonho (dream state) e não deu então o significado de um icto emocional positivo de alegria, em oposição ao sintoma do pavor. No que concerne a esta distinção Jackson deu o exemplo de um de seus pacientes que durante uma aura déjà-vu sentiu que o que mantinha sua atenção ocupada já tinha acontecido antes e, por causa disso, o fenômeno assumia "um caráter de rememoração familiar com um leve sentimento de satisfação." E conclui: "O estado de sonho não é sempre desagradável e algumas vezes pode ser positivamente agradável. Tenho ouvido pacientes dizerem que 'encorajam' essas sensações, sabendo antes que elas realmente significam sensações desagradáveis".

Gastaut conclui finalmente que até o final do século XIX os mais prestimosos epileptologistas que tinham coletado e classificado cerca de mil casos de auras epiléticas, mas que não tinham ainda conhecimento do trabalho de Dostoiévski, conheciam as auras emocionais de pavor, terror ou ansiedade, mas nem todos sabiam da existência da verdadeira euforia e, por extensão, da aura extática.

O ponto de partida para o conhecimento e divulgação da epilepsia de Dostoiévski e sua aura extática na literatura médica foi a publicação de duas teses. Uma de Loygue (1903) ${ }^{30}$ outra de Segalov (1906) ${ }^{35}$ ambas citam as crises epiléticas descritas pelo personagem de O Idiota, o principe Myschin. No entanto, sabemos que Kovalevskaya e Strakhov, consideraram o fenômeno como sendo uma aura emocional do próprio Dostoiévskis. Esta aura foi mencionada mais tarde, em 1918, no boletim semanal Progrès Medicai, datado de 16 de setembro, dedicado a uma análise de Serge Persky sobre a vida e a obra de Dostoiévski, e novamente em 1924 e 1933 nas teses de Figuière ${ }^{12}$ e Bercovici respectivamente. Nenhum desses autores, entretanto, relatou casos pessoais com aura similar àquela de Dostoiévski, sobre a qual Pauly ${ }^{32}$ em 1948 escreveu: "Esse tipo de aura psíquica é muito peculiar. Em vão, uma pesquisa feita nos vários tratados clássicos de neurologia não mostrou qualquer caso parecido".

Ainda segundo a criteriosa revisão de Gastaut, houve apenas uma publicação relatando aura extática antes do meio deste século, isto é, antes da descoberta da epilepsia do lobo temporal. Foi o trabalho de Raymond, citado por Hartemberg (1946) o qual descreveu um paciente exibindo aura extática semelhante àquele descrita por Dostoiévski ${ }^{22}$. O paciente de Raymond era uma mulher que apresentava sensação de indefinível felicidade a qual era incapaz de descrever. Ela sentia alegria e neste momento desejava morrer. Gastaut ficou convencido de que Raymond descreveu este caso influenciado por Dostoiévski que a respeito de si próprio dizia sentir "um inimaginável sentimento de felicidade", "difícil de descrever", "pelo qual se daria a vida inteira".

Pode-se admitir sem reservas que à parte a aura do principe Myschin e aquela atribuida a Dostoiévski, a aura extática ou prazerosa permaneceu totalmente desconhecida até a descoberta da epilepsia do lobo temporal em meados do século XX.

A epilepsia psicomotora foi descoberta gradualmente durante um período de aproximadamente 10 anos e só foi aceita com o extraordinário sucesso que nós a conhecemos hoje, no final de $1940^{22}$ Gibbs e $\mathrm{Gibbs}^{23}$, e Lennox ${ }^{24}$, que tinha anteriormente descrito as duas formas clássicas da entidade eletroclínica da epilepsia (então chamados de pequeno mal e grande mal) propuseram uma terceira 
forma baseados em critérios clínicos e eletrencefalograficos - a epilepsia psicomotora cujas crises seriam caracterizadas por descarga generalizada de pequenas ondas de $6 \mathrm{c} / \mathrm{seg}$ e comprometimento da consciência com ocorrência simultânea de automatismos. Mas a dificuldade de observar tais crises no eletrencefalograma fez com que se questionasse a existência dessa importante forma de epilepsia. Tais dúvidas persistiram até os estudos dirigidos pelo grupo de Montreal. Uma publicação inicial de Jasper e Kershmann ${ }^{29}$ mostrou que o diagnóstico desse tipo de epilepsia poderia ser confirmado no intervalo entre as crises pela presença de paroxismos eletrencefalograficos intercríticos de anormalidades localizadas na região anterior ou média do lobo temporal de um ou ambos hemisférios. Foi só depois do completo triunfo obtido por Gibbs ${ }^{23}$ sobre seu conceito que a comunidade científica aceitou a noção de epilepsia psicomotora, passando então a ser denominada mais frequentemente e mais corretamente como epilepsia do lobo temporal.

O caminho para a inclusão da aura extática como um dos sintomas possíveis da epilepsia do lobo temporal foi aberto por Gastaut ${ }^{22}$, que num trabalho apresentado na Segundo Reunião Européia de Eletrencefalografia (Marseille, 1952), propôs uma interpretação dos sintomas da epilepsia psicomotora como uma função da fisiologia do rinencéfalo. A mesma explicação foi repetida ${ }^{14}$ no Quinto Congresso da Liga Internacional Contra Epilepsia realizado em Lisboa, do qual um sumário foi publicado na Presse Médicale ${ }^{16}$ onde se pode ler: "A experiência que temos tido nos últimos cinco anos ${ }^{1315}$ leva-nos a concluir que, durante as crises, o paciente com epilepsia psicomotora comporta-se de maneira semelhante aos animais nos quais foram produzidas descargas epiléticas no rinencéfalo... especialmente em relação às alterações das emoções. No animal estimulado podemse ver respostas sugestivas de apreensão, medo, cólera. Nos pacientes durante a crise, podem-se ver automatismos verbais ou gestuais similarmente expressando ansiedade".

Gastaut $^{22}$ reconhece que, embora sintomas emocionais com euforia nunca tivessem sido provocados por estimulação do rinencéfalo, a porta não estava completamente fechada para a tentação dos neurologistas de completar teoricamente a lista de sintomas emocionais com auras oriundas do lobo temporal, introduzindo prazer, ou êxtase, em oposição às sensações desagradáveis anteriormente descritas. Conclui ainda que "a tentação era muito grande à medida que os neurologistas conheciam o celebrado antecedente de Dostoiévski, e o primeio passo era colocá-lo como modelo de aura eufórica do lobo temporal". Confessa ter sido um dos primeiros a sucumbir a esta atraente idéia, incluindo na análise de "100 casos de epilepsia psicomotora com foco no lobo temporal", de 1950 em diante, "automatismo comportamental expressando alegria, sentimento de contentamento, bemestar e, mais freqüentemente, de dor, medo e terror" ${ }^{\prime \prime 2}$.

Em 1951 Dongier" publicou análise clínica e eletrencefalográfica de 516 epiléticos, confirmando as afirmações de Gastaut. Em 1953, no Congresso da Liga Internacional de Combate a Epilepsia, Gastaut ${ }^{14}$ usou como exemplo de aura extática a descrição feita por Kovalevskaya referindo-se à aura de Dostoiévski. É do próprio Gastaut a observação de que desde então "minha prematura idéia tem sido seguida por outros, usando a aura de Dostoiévski como modelo de aura eufórica do lobo temporal, em particular Ionasescu ${ }^{27}$ e Chavany ${ }^{9}$ em seus volumes sobre epilepsia e, sobretudo Alajouanine ${ }^{35}$ em três artigos que representam até o momento as mais elaboradas análises sobre a epilepsia de Dostoiévski".

Podemos concluir que a descoberta da epilepsia do lobo temporal na metade deste século influenciou os epileptologistas a acreditar na existência da aura com prazer, extática. A inclusão deste sintoma nas afirmativas de Jackson complementariam teoricamente uma tríade de grupos de sintomas por ele descritos como representantes da aura psíquica: (a) aura com ilusão aperceptiva na qual podem estar presentes o déjà-vecu ou o jamais-vecu; (b) aura ideativa com pensamento forçado ou fuga de idéias; (c)aura com sintomas emotivos de desprazer, pavor, pânico e seu oposto, a alegria. Gastaut ${ }^{22}$ admite que só havia equívoco quanto ao último par de sintomas, uma vez que a aura com prazer e alegria não pode ser absolutamente aceita sem contestação.

A maioria dos autores que acreditaram na existência da aura extática agiram de boa fé e estavam influenciados pelo testemunho de amigos de Dostoiévski (Kovalevskaya e Strakov) e 
pelas publicações de Gastaut ${ }^{1416}$, Alajouanine ${ }^{14} \mathrm{e}_{\text {outros }}{ }^{9.25 .27}$. No entanto, nenhum deles jamais viu um caso de aura extática na sua prática diária e somente acreditaram em aura com sintomatologia de euforia ou êxtase com uma boa dose de reserva ${ }^{22}$. Gastaut ${ }^{22}$ admite que em 35 anos de prática médica exclusivamente dedicada à epilepsia, jamais deparou com um único caso de aura em êxtase e teve pouquíssimos casos de aura com prazer. Lennox ${ }^{22}$ em 1017 auras, encontrou apenas 9 casos de auras com prazer $(0,9 \%)$ dos quais "somente uns poucos mostravam efetivamente prazer". Penfíeld $^{33}$, em seus livros e artigos publicados de 1947 até 1958 concernentes a mil explorações neurocirúrgicas de pacientes com epilepsia do lobo temporal, cita somente um caso com Kristiansen ${ }^{33,34}$. Este paciente apresentava sensação de prazer precedendo a crise, acompanhado de desconforto epigástrico e seguido de percepção ilusória. Sobre este paciente e antes, referindo-se a Dostoiévski, Penfíeld ${ }^{33}$ escreve: "É verdadeiramente raro que um paciente tenha uma aura com prazer como a descrita por Dostoiévski". Alajouanine ${ }^{1.2} \mathrm{em}$ dois artigos, relata ter encontrado somente um caso de aura extática entre seus pacientes. Escreveu: "Um de meus pacientes apresentava sensação epigástrica, uma espécie de contração, seguia-se a impressão de alguma coisa como prazer, na qual sentia uma agradável sensação de ser transportado por asas em direção ao céu e que sua alma se ampliava e entrava numa espécie de liberdade, antes de perder a consciência. É possivel que os pacientes que assim se referiam às suas crises também fossem portadores de sífilis, e que esta doença tenha contribuido de alguma forma para influenciar seu estado emocional".

Finalmente podemos concluir que, em decorrência da descoberta da epilepsia do lobo temporal, dos novos conhecimentos adquiridos sobre as funções do sistema límbico, da existência de sintomatologia psíquica como desprazer, terror ou medo (e, por analogia, prazer e êxtase) como sintomas de crises na epilepsia do lobo temporal, e sobretudo devido à influência das descrições atribuidas a Dostoiévski sobre suas próprias crises de êxtase, os epileptologistas, liderados principalmente por Gastaut e Alajouanine, tenham se deixado influenciar e abusado do conceito de aura em êxtase. Tais afirmativas não invalidam por outro lado, a existência de sensações fugazes, embora raras, referidas como agradáveis ou prazerosas, pelos pacientes portadores de epilepsia do lobo temporal, como os dois casos relatados neste antigo, os únicos apresentando auras como sensações agradáveis registrados por nós em quase vinte anos atendendo pacientes epiléticos.

\section{REFERÊNCIAS}

1. Alajouanine T. Sur une épilepsie focale: l'epilepsie temporale. In: Acquisitions Médicales Récentes. Paris: Flammarion, 1951.

2. Alajouanine T. Sur un équivalent épileptique: l'absence à début psycho-affectif. Bull Acad Natl Med 1951, 135: 389-391.

3. Alajouanine T. Dostoievsk épileptique Le Nouveau Commerce cahier 1963, 2: 114-133.

4. Alajouanine T. Dostoievski's epilepsy. Brain 1963, 86: 209-218.

5. Alajouanine T. Littérature et épilepsie. In: Cahiers de I'Herne. N. 24: Dostoievski. Paris: Editions de I'Herne, 1973, p 309-324.

6. Antoni N. Dream states, epileptic aura, depersonalization and psychasthenic fits. Acta Psychiatr Scand 1946, 21: 1-20.

7. Bercovici L. Dostoievski, étude de psycho-pathologie. Thèse. Paris, 1933.

8. Catteau J. La Creation Litteraire Chez Dostoievski. Thèse de Doctorat d'Etat. Paris. Sorbonne.

9. Chavany JA. Épilepsie: étude clinique, diagnostique, physiopathogéniqueet thérapeutique. Paris: Masson, 1958.

10. Delasiauve (le Docteur). Traité de l'epilepsie. Paris: Masson, 1854.

11. Dongier S. Statistical study of clinicai and electroencephalographic manifestations of 536 psychotic episodes occurring in 516 epileptics between clinicai seizures. Epilepsia 1960, 1: 117-142.

12. Figuière J. L'épilepsie dans l'oeuvre de Dostoievski. Thèse Lyon, 1924.

13. Gastaut H. Corrélations entre le systéme nerveux végétatif et le systéme de la vie de relation dans le rhinencéphale. J Psysiol 1952, 44: 431-470.

14. Gastaut H. So-called "psychomotor" and "temporal" epilepsy: a criticai study. Proc 5th Internat Congr League Against Epilepsy. Epilepsia 1953, 2: 59-84.

15. Gastaut H. A-propos des fonctions non-olfactives du rhinencéphale. J Psysiol 1953, 45: 117-120.

16. Gastaut H. Interprétation des symptomes de l'epilepsie psychomotrice en fonction des données de la psysiologie rhinencéphalique. Presse Med 1954, 74: 1535-1537.

17. Gastaut H. Broughton R. Ataques epiépticos. Barcelona: Toray, 1975, p 119. 
18. Gastaut H. La maladie de Vincent Van Gogh envisagée à la lumière des conceptions nouvelles sur l'épilepsie psychomotrice. Ann Med Psychol Paris 1956,'2:1-43.

19. Gastaut H. Clinical and electroencephalographical classification of epileptic seizures. Epilepsia 1970, 11: 102-113.

20. Gastaut H, Dongier M. Sur les troubles psychiques de l'épilepsie dite temporale. Bull Soc Clin Hôp Charleroi II 1951, 3 July.

21. Gastaut H, Gastaut Y. Correlations eletroencephalographiques et cliniques à-propos de 100 cas d'épilepsie psychomotrice avec foyer temporal. Rev Otoneuroophtalmol 1950, 257-282.

22. Gastaut H. Fyodor Mikhailovitch Dostoyevsky's involuntary contributin to the symptomatology and prognosis of epilepsy. Epilepsia 1978, 19: 186-201.

23. Gibbs El, Gibbs FA, Fuster B. Psychomotor epilepsy. Arch Neurol Psychiatry 1948,50:331-339.

24. Gibbs F, Gibbs E, Lennox W. Epilepsy, a paroxismal cerebral dysrhythmia. Brain 1937,60:377-388

25. Gowers WR. Epilepsy and other chronic convulsive diseases. London: J and A Churchill. 1881.

26. Herpin T. Du prognostic et du traitement de l'épilepsie. Paris: Bailliére 1852.

27. Ionasescu V. Epilepsia temporala. Bucaresti: Editura Medicala, 1957.

28. Jackson JH. Selected writings of John Hughlings Jackson, Vol 2, J Taylor (ed). New York: Basic Books, 1958.

29. Jasper H, Kershmann J. Eletroencephalographic classification of the epilepsies. Arch Neurol Psychiatry 1941, 45: 903-943.

30. Loygue PG. Étude médico-psychologique sur Dostoievski: considérations sur les états morbides liés au genie. Thèse. Lyon, 1903.

31. MacRae D. Isolated fear, a temporal lobe aura. Neurology 1954, 4: 497-505.

32. Pauly R. L'épilepsie de Dostoievski. J Med Bordeaux 1948, 125; 337-345.

33. Penfield W, Jasper H. Epilepsy and the functional anatomy of the brain. Boston: Little, Brow and Co. 1954.

34. Penfield W, Kristiansen K. Epileptic seizure patterns. Sprinfield: Charles C Thomas, 1951.

35. Segalov T. Die Krankheit Dostoiewskis. Thesis. Heidelberg, 1906.

36. Voisin J. L'épilepsie. Paris: Germer Vaillière, 1897. 